\title{
Ideological Focus, Tactical Performance, and the Survival of Terrorist Organizations
}

\author{
Susan Olzak \\ Department of Sociology \\ Stanford University \\ Word Count 9826 (abstract, text, references, tables, and footnotes)
}

November 12, 2020

Corresponding author: Professor Susan Olzak, Department of Sociology, Stanford University, Stanford CA. olzak@stanford.edu

*Acknowledgements: The author would like to thank Todd Sandler, Donfang Hou, and Krushav Gaibulloev for their ETDG dataset and for helpful advice during the course of this research. The author thanks Sarah Soule and Mike Hannan for providing useful advice and suggestions on earlier drafts. 
Ideological Focus, Tactical Performance,

and the Survival of Terrorist Organizations

\begin{abstract}
Organizations that have a clear focus acquire greater reputational legitimacy, which raises their capacity for mobilization. Using data on terrorist organizations, this paper explores two empirical implications of this claim: A terrorist organization's survival and lethality will be threatened to the extent that it has an ambiguous identity. Analyses using panel data from the Extended Data on Terrorist Groups (EDTG) test these arguments for nearly 500 terrorist organizations observed over 1970-2016. The key empirical predictions are that ambiguity inhibits lethality and curtails survival. Moreover, ambiguity curtails a TO's longevity most during the very early years of its operation, consistent with the liability of newness argument. This paper finds support for these claims, controlling for competition of rivals and allies, ethno-nationalist or Islamic ideological orientation, tactical diversity, size, international operations, and other measures of organizational capacity.
\end{abstract}


Despite numerous studies, there is little consensus about which characteristics allow terrorist organizations (hereafter TOs) to flourish. ${ }^{1}$ This dissensus can be explained partly by the fact that most TOs operate as clandestine organizations that seek to avoid scrutiny (della Porta 2013). Moreover, the boundaries separating terrorist groups from criminal gangs, armed rebellions, and military coups are porous, which makes it difficult to track group activities over time. And, as many have noted, one man's terrorist is another man's freedom fighter (Tilly 2004).

To gain some leverage in the face of these challenges, I build on a theory of concepts and categories that explains why having a clearly-focused identity ought to affect the functioning of many types of organizations. Work building on this theory finds that organizations with a clear focus perform better and survive longer when compared to those with an indistinct focus (Hannan et al. 2019; Kovács and Hannan 2010). I argue that having a distinct focus ought to benefit TOs in the same way.

To gain precision about the scope of inquiry, I adopt Phillips' (2015: 63) definition of terrorism as: "the use or threat of violence by non-state actors for the purpose of inciting fear in a much wider audience to bring about political change." This definition requires that TOs have one or more political goals, which helps distinguish them from other sorts of violent organizations, including criminal organizations and drug cartels.

The paper tests the idea about issue focus using the newly available dataset on TOs from the Extended Data on Terrorist Groups (hereafter EDTG), which is based on the Global Terrorist Database (GTD). The GTD provides a chronological listing of (researcher verified) terrorist events and if known, the names of perpetrator groups, but it does not provide organizational characteristics of size or ideology. The EDTG dataset offers an unusually comprehensive picture

\footnotetext{
${ }^{1}$ For reviews, see Sandler $(2014,2015)$ and Schuurman and Taylor (2018).
} 
of key organizational features of TOs over an extended (1970-2016) period (see Hou, Gaibulloev, and Sandler 2020).

I investigate two outcomes relevant to a TO's functioning: the counts of casualties it causes and its survival over time. An underlying assumption is that TOs engage in lethal (as well as other) tactics in order to spread fear (Valentino 2014). A second underlying assumption is that, as with all organizations, members of terrorist organizations want them to survive (Gamson 1975). I analyze fatalities and endings of terrorist organizations to assess the relative influence of resources, age, and issue focus on these outcomes.

\section{PRIOR RESEARCH}

What do we know about the tactical performance and survival of terrorist groups? Key studies have focused mainly on the number of attacks and/or fatalities generated (e.g., Asal and Rethemeyer 2008; Hou et al. 2020) or on the longevity of the organizations (e.g., Blomberg, Engel and Sawyer 2010; Blomberg, Gaibulloev, and Sandler 2011; Cronin 2009). Scholarship on terrorist organizations also finds more lethal TOs have an international scope, or more intra- and inter-group rivalries, or dominate and out-perform rivals, or hold a central network position (Asal et al. 2016; LaFree, Dugan, and Miller 2015; Phllips 2019; Sandler 2014; Valentino 2014; Young and Dugan 2014). Others find that the demise of a TO's leader and the scope of its transnational activities significantly decrease its chances of survival (Hou et al. 2020; Olzak 2016).

One consistent finding from terrorist research points to the centrality of ideology in shaping the performance and survival of TOs: Those with religious and/or ethnic identities kill more victims (Asal and Rethemeyer 2008; Asal and Rethemeyer 2009; Asal and Phillips 2015; 
Berman 2009; Blomberg et al. 2011; Cronin 2009) and survive longer than do those associated with other ideologies (Hou et al. 2020; Jones and Libicki 2008; Piazza 2009; Phillips 2014).

Theories of social movement organizations (SMOs) also specify that narrow specialization ought to assist organizations in performing routine activities and attaining goals because it streamlines coordination processes (McCarthy and Zald 1977: 1234). If TOs can be considered a subset of SMOs (Beck 2008; Olzak 2016), then having a clear focus would help explain why religious and ethno-nationalist terrorist groups generate higher casualty rates: ideological clarity is arguably greater in single-identity religious and ethnic organizations, as compared to organizations that have multiple ideologies (Asal et al. 2015). I next consider how an organization's identity is linked to the clarity of its focus.

\section{AMBIGUITY}

Ambiguity refers to a lack of focus. In technical terms the ambiguity of an object increases the sum of the probabilities that it can be classified as an instance of each of the relevant concepts (or ideologies). A concept is a mental representation of an object that generates expectations about its meaning. An object that can plausibly classified in any number of ways is hard to interpret.

Ambiguity is a characteristic of a position in a semantic space (defined as the set of values of the relevant features of an entity). Hannan et al. (2019: 164) propose that "objects represented as positions with a high categorization probability for only one concept have low conceptual ambiguity; positions that have an even distribution of categorization probabilities have maximal conceptual ambiguity." Put differently, objects (or actors, or organizations) with mental representations of high ambiguity are more likely to be assigned to multiple concepts. In formal terms the ambiguity of the object $o$ is defined as: 


$$
A(o)=\sum_{c \in \mathrm{C}} P(d \mid x) \log (P(d x))
$$

where $C$ denotes the set of potentially applicable concepts. $P(d x)$ is the probability that an organization with relevant feature values summarized as $x$ would be categorized as an instance of c.

The key substantive claim is that ambiguity lowers fluency, which is the ease of processing information about an object. Considerable psychological research finds that disfluency gives rise to negative affect and lowers appeal (Alter and Oppenheimer 2008). Ambiguity ought to have a similar negative effect on valuations of terrorist organizations.

Consider what conditions would produce the maximum ambiguity for a TO with features that plausibly fit two ideologies (for example, ethnic-nationalist and right-wing). ${ }^{2}$ According to Hannan et al. (2019, organizations whose feature values cause it to have an equal probability of being assigned to either ideology have maximum ambiguity, while those that are more clearly judged as mainly assigned to a single ideology (e.g. just ethno-nationalism) would have lower ambiguity.

\section{Focus and Performance}

Why would we expect focus to influence the tactical performance of TOs? Having a highlyfocused identity allows an organization's culture to be easily interpreted (Sørensen 2002). The recognition that an organization is a member of a category influences how people think about it,

\footnotetext{
${ }^{2}$ Five organizations in the EDTG dataset I use were assigned these two labels: Anti-terrorist Liberation Group (GAL), Eritrean Peoples' Liberation Front, Fatherland and Liberty Nationalist Front (Chile), Mozambique National Resistance Movement (MNR), and the National Union for the Total Independence of Angola (see Table 1 for listing of the frequency of all labels).
} 
especially how they process information about it. When organizations are well understood, they are also more likely to be perceived as reliable (Selznick 1960). Such perceptions of reliability further increase an organization's confidence in performing difficult tasks, which is relevant when considering the array of dangerous activities that are part of a TO's repertoire.

Organizational affiliation with a well-known ideology—-for instance, Marxist, Islamic, Separatist, etc., provides a recognizable rationale for committing terrorist acts. A focused ideology offers a way to place the motivation for violence within an understandable context (Chou 2016). Conversely, ambiguous ideological affiliations raise doubts about its claims that violent tactics are necessary.

When an organization's ideological identity is evaluated as ambiguous or inauthentic, its ability to attract resources and members is diminished. Having an unclear and ambiguous identity would reduce media attention, which is a key resource for all SMOs. Such negative evaluations might be understood in terms of reputational legitimacy, meaning that an audience (comprised of insiders, scholars, the media, and others) casts doubt on a given organization's capacity to spread fear. Less legitimate organizations seen as weak become more vulnerable to attack by authorities and rivals, which tarnishes their reputations even further (Davenport 2015). Ambiguity and Longevity

TOs frequently dissolve due to acts of betrayal, internal conflict, attacks by rivals or authorities, and leadership struggles (Asal and Young 2012; Chou 2016; Crenshaw 1991, 2011; Cronin 2009; Davenport 2015; della Porta 2013; LaFree and Dugan 2009; Young and Dugan 2014). The clarity and sharpness of a TOs categorical memberships in a recognizable ideological camp ought to increase its capacity for suppressing internal conflicts, which also helps resolving disputes over leadership succession (Cronin 2009). Like all social movements, TOs rely on 
mechanisms that increase internal solidarity and loyalty, which can be undermined if some of its members express doubt about an organization's focus.

Organizations that straddle multiple ideological categories likely attract a heterogeneous pool of followers. Such membership heterogeneity in turn increases an organization's vulnerability to internal conflicts, leadership disputes, and other common sources of terrorist splits (Asal, Brown, and Dalton 2012; Cronin 2009; della Porta 2013). Indeed, Davenport (2015) claims that along with repression, internal disputes are a key cause of a SMO's demise.

Organizations with ambiguous identities likely have fissures within the membership that can undercut leadership authority (La Free and Dugan 2009). Loss of authority undermines an organization's ability to maintain morale and discipline, which hampers efforts to accomplish missions. In contrast, ideological purity can strengthen a leader's authority, which allows an organization to act decisively when facing a threat (Berman 2009). If this argument holds, then ideological clarity would also improve a TOs chance of survival (Conrad and Greene 2015; Cronin 2009).

\section{Ambiguity and Recruitment}

Finally, having low ambiguity in some ideological category ought to streamline the recruitment process by framing difficult actions (such as suicide bombing) as required by a movement's core ideology. Individuals will be attracted to those ideologies that gives them sense of higher purpose. According to Webber, et al. (2020: 108), "Ideologies, then, can promote violence if they associate political goals with the need to feel significant." TOs with coherent and wellunderstood ideologies are better positioned to make these claims.

Recruits regularly enter TOs and existing members leave them, which creates difficulties for maintaining continuity and commitment (Cronin 2009; della Porta 2013). When an audience 
assigns membership in a single recognizable ideology to a TO, it can attract those most committed to that cause.

TOs advertise their identities by regularly posting mission statements and manifestos on social media. Kinney, Davis and Zhang (2018) analyzed some of these postings and found that a TO's use of distinctive semantic themes signal its ideological commitment and legitimacy, which aids in recruitment. Coordination costs will be lower to the extent that a TO's identity as a Marxist, or Islamicist TO can be taken for granted (Post, Sprinzak, and Denny 2003). Overall, having a sharp ideological focus reinforces engagement of members who can be induced to commit violence on innocent civilians.

\section{DATA AND MEASURES}

This analysis uses a newly available and comprehensive data set (EDTG), created by Hou et al. (2020), which is comprised of data on 760 terrorist organizations listed by names and dates of attack in the Global Terrorism Database (GTD). GTD's inclusion criteria include the provision that a terrorist act is intentional, includes some level of violence or immediate threat, and its perpetrators are sub-national (non-state) actors. In addition: “(1) The act must be aimed at attaining a political, economic, religious, or social goal, (2) There must be evidence of an intention to coerce, intimidate, or convey some other message to a larger audience (or audiences) than the immediate victims (3) The action must be outside of the context of legitimate warfare activities" (GDT Codebook 2019: 10). EDTG researchers discarded events that had no known perpetrator, were difficult to verify, or were of uncertain or even questionable origin. The list of organizations in EDTG are those with organizational characteristics that could be identified and verified. 
Using LEXIS/NEXIS, Mapping Militants, Rand Corporation, Wikipedia, I then crossvalidated all information on each named organization. Many organizations are also consistently identified by scholars, the media, and archives by adding initials after their name (e.g. South West African People's Organization or SWAPO), which greatly assists distinguishing among similarly-named organizations. Location of operations, leadership names, and other corroborating factors were also used here to cross-check the data.

\section{EDTG Dataset}

Researchers Huo et al. (2020) used GTD's information on the subset of events with known perpetrators as a basis for building a time-series dataset at the organizational level. They collected, coded and verified information on 760 groups that operated between 1970 and $2016 .{ }^{3}$ The unit of analysis is an organizational year, arranged chronologically from 1970 on, so that each organization's history begins with its first attack listed and ends in 2016. The EDTG dataset collected information on organizational features, taking care to identify numerous spelling differences, name changes, and other relevant characteristics. ${ }^{4}$ Due to missing data on size, fatalities, number of attacks and other measures, Huo et al. (2020: 217) full model analyzed 339 organizations. I tracked down some of this missing data and my final dataset includes 483 organizations with full information on organizational characteristics and lethality and 487

\footnotetext{
${ }^{3}$ Four organizations were omitted due to duplication and verification of records with all other sources listed below (and with an updated version of GTD).

${ }^{4}$ See https://journals.sagepub.com/doi/suppl/10.1177/0022002719857145 for the EDTG replication dataset and Codebook.
} 
organizations with full information on survival. For the 487 organizations in the analysis of endings, fifty-six percent (273) had ended before the end of 2016.

\section{Lethality}

One measure of tactical performance of TOs used by a variety of researchers counts the number of fatalities generated. ${ }^{5}$ This research tradition treats fatalities as part of a TO's tactical repertoire, but it does not assume that fatalities are desired objectives (though they may be). The analysis builds on this tradition by exploring the effects of ambiguity on lethality: the annual number of civilian deaths from attacks in which a named organization was listed as responsible by GTD, cross-validated by researchers Hou et al. (2020), and re-checked by this author.

Note that some researchers Sandler (2014), Olzak (2016)) have used the ratio of deaths per attack, while others use a straightforward count of fatalities. To distinguish the influence of lethality from the volume of attacks, I specify a model that sets an exposure parameter to 1 to control for effect of the number of attacks generated. The reasoning here is that number of deaths in a year depends upon an organization generating one or more attacks in that same year (Clauset and Gleditsch 2012). Hou et al. (2020: 5) define this measure as "the total number of deaths caused by a terrorist group in a given year." These authors also measure "total casualties" defined as the combined count of deaths and injuries in their dataset. Replacing total deaths with casualty measures in the analysis shows no significant differences.

\section{How Terrorist Groups End}

${ }^{5}$ For examples, see Asal and Rethemeyer (2008), Asal, Gill, Rethemeyer and Horgan (2015)

Asal et al. (2016) and Piazza and LaFree (2019). 
The second dependent variable is the rate of ending by various means, with an organization's observed lifetime measured in years that elapse from an organization's first observed attack (beginning in 1970) through the last recorded attack of violence or the end of the observation period. An organization's ending event was first coded by EDTG researchers and validated by this author, using all of sources listed in the next section. An ending occurs with respect to its continuation as an organizational entity indicating that it no longer operates as a single cohesive organization. Endings include joining the political process (or achieving its goals), splitting, military defeat, fading away ${ }^{6}$ or merger.

All endings imply that the TO has stopped generating terrorist activity by the end of 2016 (but note that it may experience a resurgence after that date). I focus on three ending events: ending by any means (including mergers), and two subset endings: by entering the political system, and by ending badly, by splitting, military defeat, or fading away. As discussed below, I do not analyze merger endings in the last category of endings because they (1) do not fit the same criteria of organizational demise in the same ways as do other ending categories, (2) more importantly, might be evaluated as either a negative or positive outcome from an organizational perspective, depending on who is evaluating the outcome.

Sources of Information on Ideological Assignments

Coding of ideological categories was conducted by this researcher by systematically searching all archives for each organization by name, alias, using different spellings uncovered by EDTG,

\footnotetext{
${ }^{6}$ Fading away is coded as such if no activity was recorded by a group since 2012 and if no other ending events could be verified (see also Gaibulloev and Sandler 2013; Horowitz and Potter 2014 for similar coding rules).
} 
GTD, Mapping Militants, Jones and Libicki (2008), and Asal, Rethemeyer and Anderson (2008).Most datasets on terrorist groups (e.g., Asal et al. 2008; Huo et al. 2020; Jones and Libicki 2008), assign just one ideological label for each organization. In contrast, other sources such as Mapping Militants (Crenshaw 2020), Tracking Terrorism (2020), Wikipedia, the South Asian Terrorism Portal, the Guardian and the BBC often assign more than one ideological affiliation. Evaluating my theoretical argument requires that I take any ideological affiliation into account that was attributed to a TO. I code a TO as an instance of an ideology if any of the following sources associated a named organization with an ideology:

1. BBC online (available at http://bbc.com),

2. Lexis-Nexis News Database (lexisnexis.com)

3. Mapping Militants ( http://web.stanford.edu/group/mappingmilitants/cgibin/bin/), 4. ProQuest Historical Newspapers Database (Newsbank)

5. RAND Database of Worldwide Terrorism Incidents (RDWTI) (http://smapp.rand.org).

6. South Asia Terrorism Portal (SATP)(http://www.satp.org).

7. Big Allied and Dangerous (BAAD) (https://www.start.umd.edu/baad/database)

8. Terrorism Research \& Analysis Consortium (TRAC) (http://www.tracterrorism.org),

9. Reuters News. (http://www.reuters.com/news)

10. Wikipedia ( http://en.wikipedia.org).

This finite set of ideological labels were assigned either separately or in combination: ethno-nationalist, leftist/Marxist, right-wing, religious-Islamicist, religious-not-Islamic, antiglobalization, environmental, anarchist, racist, tribal, and other (e.g., not elsewhere classified). Given the heightened interest surrounding violence involving Islamic TOs (Asal et al. 2015), I distinguish Islamic-Religious from Non-Islamic Religious (many scholars use only one category 
for "religious"). However, the category of "tribal" is somewhat unusual and therefore deserves discussion. An organization was listed as "tribal" only if it was accompanied by these phrases "distinctly not ethno-nationalist" and "distinctly not religious." The final dataset shows that the number of ideological affiliations ranges from one to three categories.

\section{Ideological Focus and Ambiguity}

The measure of ambiguity requires estimates of the probability of categorization in each ideological category. Appendix A provides the details of how categorization probabilities are obtained from the categorization data.

Table 1 displays all of the labels attributed to the TOs analyzed in the fatality analysis. First, note that the vast majority (67.7 percent) of organizations have a singular focus, while another 30 percent have been assigned only two labels, with a small (2.7) percent spanning three categories. For TOs assigned to more than one ideological label, ambiguity depends both on the number of labels and the relative frequency of that combination compared to distribution of organizations in all other pairs of labels. Concretely, this means that assigned combination of Ethno-nationalist and Religious Non-Islamic ideologies is less ambiguous than the combination of Ethno-nationalist and Religious-Islamic (the ambiguity measures are .235 versus .712, respectively).

[Table 1 about here]

\section{Control Variables}

Relevant characteristics of TOs from EDTG dataset were supplemented with additional sources of data noted below. Table B.1 in Appendix B reports the means, standard deviations, and a correlation matrix of all covariates in the analysis of fatalities (the statistics for organizations included in the analysis of endings are nearly identical). 
Allies and Rivals. Research by Phillips (2015) finds that TOs operating in the same geographical location with other terrorist groups and within a similar ideological category are less lethal and are more likely to die than organizations without rivals. Nemeth (2013) finds that nationalist and religious groups respond with more violence when they are in competition with rivals. Asal et al. (2016) find that TOs with similar ideology (especially religious ideologies) and that operate in the same region are likely to establish alliances. I rely on the EDTG dataset coding for the presence of one or more rival(s) if the focal terrorist group competes with another terrorist group for the same goal in that year. The same strategy is used to calculate a dummy variable for the presence of one or more allies. Missing data was supplemented with Phillips' (2014) rivalry data. Both the rival and ally measures are updated annually.

Peak size. Establishing the precise size of a clandestine organization is notoriously difficult, however, the Extended Data on Terrorist Groups (EDTG) project provided two estimates: size (which can vary over years), and peak size, which is defined as the largest recorded number of members at some point during an organization's existence. Virtually all studies of lethality and survival of TOs find that an organization's size improves its performance and extends its longevity (Asa et al. 2015; Asal and Rethemeyer 2008; Blomberg, Engel and Sawyer 2010; Blomberg et al. 2011; Clauset and Gleditsch 2012).

Peak size ignores temporal variation, but it is available for a greater number of cases (more than $50 \%$ of the organizations in the EDTG dataset have no annual data on size). I identified cases with missing "peak size" in EDTG and supplemented information on this measure using information found on the Mapping Militants website (Crenshaw 2020), the South Asian Terrorism Portal (SATP), and Jones and Libicki (2008). 
Tactical diversity. The EDTG dataset defines this measure as an index calculated by one minus the Herfindahl-Hirschman index,

$$
\text { Diversity }=1-\sum_{i} S_{i j t}^{2}
$$

Where $S_{i j t}^{2}$ is the share of the $i$ th type of terrorist attack in total identified attacks for group $j$ in year $t$. ETGD lists nine tactics: assassination, hijacking, kidnapping, barricade incident, bombing/explosion, armed assault, facility/infrastructure attack (unknown is omitted from the calculation).

Share of Transnational Events. This is the proportion of a TO's events that were transnational in a year. It is calculated as the number of transnational terrorist attacks divided by the sum of domestic and transnational events attributed to that group (Enders, Sandler, and Gaibulloev 2011). Note that this variable is coded as zero if an organization only operates domestically (in its home base country) in a given year. Substituting this measure with a dummy variable indicating international scope showed no differences in effects on either fatalities or endings. Duration. The EDTG dataset uses a clock that begins in 1970 (when GTD observations begin) to estimate a TO's duration. It is calculated beginning in the first year of a TO's first attack, through its demise (or through 2016 if it is still active). This variable ranges from 1 (first year of verified terrorist activity) to 47 . This variable is highly skewed and so its natural log was calculated to take this into account.

Organizations Active Before 1970. Some TOs listed in GTD as active in 1970 were active long before that date. To distinguish this cohort from other TOs, I consulted Rand Database of Worldwide Terrorist Incidents, Mapping Militants, BAAD1, and Wikipedia to assess whether a given organization committed terrorist acts prior to 1970. This variable was coded 1 if an organization was active prior to 1970, zero otherwise. 
Number of Bases. This measure indicates the annual number of base countries of operation, which partly indicates the international scope of its operations (see Huo et al. 2020 for details). Period Effects. Patterns of lethality and organizational demise may shift considerably in reaction to watershed events, especially those involving major terrorist attacks. To explore this notion, a dummy variable was included in the analysis: Post 9/11, which equals one for years after 2001. ${ }^{7}$

Leadership Fate. This is a dummy variable that indicates that a leader was either killed or arrested in a given year. It can happen multiple times during a TO's lifespan and thus it is not necessarily coterminous with an organization's demise (correlation is .06). Both indicators of a leader's removal have the same effect on and so were combined into a single measure. There is no prior theory to suggest this measure affects fatalities and it had no effect of fatalities and so was dropped from the analysis of fatalities. It is highly relevant to organizational endings and so is included in those analyses.

\section{ESTIMATION}

The analysis of lethality uses annual counts of fatalities attributed to a given organization by the GTD researchers. EDTG researchers further cross-validated this information, using a variety of news media sources (see Hou et al. 2020). These counts (like most event count data) are overdispersed, which means that standard deviations exceed the mean values. For longitudinal count data with overdispersion, negative binomial panel models are appropriate and so were chosen for this first analysis. I use random effects models because several key theoretical

\footnotetext{
${ }^{7}$ Replacing this with an annual time trend reveals a similar negative effect on fatalities and a positive effect on endings.
} 
variables (ambiguity, typicality, and peak size) are time invariant and so fixed effects models would not be appropriate.

The second dependent variable is the hazard of ending by various causes, with the lifetime measured in years that elapse from an organization's first observation through ending date (validated by Huo et al. 2020 and again by this author). Given the importance of aging found in prior analyses (Young and Dugan 2014; Blomberg et al. 2011), it seems important to specify a model that allows the effects to vary by age. I begin the analysis with a flexible piecewise-exponential model, which allows the hazard to vary in an unconstrained manner at preselected ages (which I determined by the cumulative hazard curves and other diagnostics). I divide the age range at two points: 0 to 9 years and 14+ years. Survival times vary broadly, from one to 47 years, with a mean survival of 13.7 years. Use of the piecewise exponential parameterization, in which each age segment has its own baseline rate of failure, allows us to examine all the possibilities of age dependence implied by the liability of newness, adolescence, or senescence (Stinchcombe 1965)

The specific hypotheses are:

H1: Terrorist organizations that have high ambiguity will cause fewer casualties per year than organizations that have relatively low concept ambiguity.

$\mathrm{H} 2$ : Terrorist organization that have high ambiguity will be less likely to survive and will be more likely to likely to end, especially ending by splits, military defeat, or by fading away.

\section{RESULTS}

Table 2 presents estimates from the negative binomial regression analysis that highlights the effect of ambiguity. How does the ambiguity argument fare? Compared to organizations with a 
narrow focus, organizations with high ambiguity have significantly diminished lethality as compared to belonging to one category, as expected by hypothesis 1 . The coefficient of -.450 in column 1 indicates that, compared to an organization assigned a single ideology of ethnonationalist (ambiguity is 0), a TO assigned to both ethno-nationalist and leftist categories (ambiguity is .635) would have its lethality reduced by twenty-five percent (net of the effects of the other covariates and controlling for number of attacks).

[Table 2 About here]

The influence of ambiguity on fatalities is robust across a number of specifications, net of the non-trivial effects of other organizational features. The results remain the same when the outlier case of al-Qaeda is removed. Together, these finding lend support for the argument that ideological clarity aids the performance of one key tactic used by terrorists.

If competition from rivals reduces the pool of resources available to any one terrorist organization, then rivals could constrain an organization's performance. We see evidence supporting this view in both columns in table 2 (but see Phillips 2015). Interestingly, having an ally (with the same goals) also diminishes an organization's fatalities significantly.

Why would the presence of allies reduce lethality? One possibility is that weaker and less lethal terrorist organizations actively seek out more powerful allies to bolster their position (Asal et al. 2016; Bapat and Bond 2012; Phillips 2019). One way to examine this argument would be to see if smaller organizations (presumably weaker ones) are more likely to have allies (Phillips 2019). In the current dataset, peak size and allied status are weakly and positively correlated (.08), which runs counter to this explanation.

A key measure of organizational strength is peak size, which shows a significant and positive effect on fatalities, as others have found (Gaibulloev and Sandler 2013; Hou et al. 2020; 
but see Clauset and Gleditsch 2012) This finding resonates with organizational studies that find that there are advantages to size, allowing them to benefit from economies of scale (e.g., see Carroll and Hannan 2004; Le Mens, Hannan, and Polós 2011). However, given the crosssectional nature of this measure (and the difficulties in estimating growth or decline), this finding should be taken with caution. Organizations that perform well are also more likely to attract more recruits.

Tactical diversity significantly decreases lethality of organizations, as the negative coefficients -.260 reveals in table 2 . This evidence supports the general argument about the benefits of specialization offered earlier. In this view, organizations aiming to be a "jack of all trades" has disadvantages (see Hsu 2006). However, if one considers tactical diversity a sign of organizational strength, then this finding runs counter to expectations (see Blomberg et al. 2011). Organizations that operate from multiple bases are more lethal. However, because the causal direction cannot be identified with precision, these findings should be viewed cautiously.

The findings in table 2 replicate earlier analyses by many scholars that find religious and ethno-nationalist organizations are significantly more deadly. Ethno-nationalist and Islamist organizations are more lethal, net of the effect of ambiguity and typicality. As might be expected, TOs existing prior to 1970 had more fatalities (but duration was negatively associated with fatalities for other TOs). The decline in fatalities post $9 / 11$ hints at the possibility that counterterrorism has decreased fatalities.

\section{Proportion Hazard Model of the Rate of Ending}

The data on each organization, $i$, is updated annually, beginning with the year of the first observed event through its specific ending year (or remains censored). Given that different durations and ending types can be identified, it seems reasonable to consider a flexible model 
that compares the competing risks of ending $(\lambda \mathrm{i}(\mathrm{t} \mid \mathrm{xi})$ in a specific way. I use a proportional hazard model that estimates the effects of the covariates $(\boldsymbol{x})$ on the rate of endings, which takes into account that the rate can change over the course of an organization's lifespan. The standard form is:

$$
\lambda \mathrm{i}(\mathrm{t} \mid x \mathrm{i})=\lambda 0(\mathrm{t}) \exp (\boldsymbol{x b})
$$

I partition duration into $\mathrm{J}$ intervals with $0=\tau_{0}<\tau 1<\ldots<\tau \mathrm{J}=\infty 0=\tau 0<\tau 1<\ldots<\tau \mathrm{J}=\infty$. I define the $\mathrm{jth}$ interval as $[\tau j-1, \tau j)[\tau j-1, \tau j)$, extending from the $(j-1)(j-1)$ st boundary to the $j \mathrm{j}$-th. The piecewise baseline hazard is constant within each interval (or pieces), so that

$$
\lambda 0(\mathrm{t})=\lambda \mathrm{j} \text { for } \mathrm{t} \text { interval }[\tau j-1, \tau \mathrm{j})
$$

Thus, I model the baseline hazard $\lambda 0(\mathrm{t})$ using $\mathrm{J}$ parameters $\lambda_{1} \ldots, \lambda_{\mathrm{J}}$, each representing the risk for the reference group in one particular interval. Since the risk is assumed to be piece-wise constant, the corresponding survival function is called a piece-wise exponential. The first twoyear interval captures the theoretical argument that an organization's first years of operation are most hazardous. The second cut-off point was chosen based upon inspection of cumulative hazard plot (Nelson-Aalen), in which the hazard of ending levels off at around fourteen years.

The evidence in table 3 supports the common "liability of newness" hypothesis: in all six columns, the rate declines substantially after two years. Note however, that the rate of entering politics system first drops between 0 and 14 years, and then rises again after twenty-one years of existence, while ending by all other means continues to decline throughout old age.

[Table 3 about here]

Table 3 present piecewise exponential estimates of the rate of ambiguity on ending outcomes: Column (1) examine the rate at which an organization ends (by any means) in a given year; Column (2) examine the rate at which an organization ends by joining the political system; 
Column (3) examines the rate at which an organization ends by military force, internal conflict, or fading away. A TO's ending by merger seems qualitatively different when compared to an organization's ending due to splits, military defeats, or fading away, and so endings by merger were excluded from the analysis shown in column (3). However, the results show no difference when mergers are included (however, when mergers are included, the positive influence of ambiguity becomes stronger).

Hypothesis 2 regarding issue focus receive support for all endings and for endings that do not involve entering the political process, controlling for numerous factors prior research has identified as important. The coefficient of .417 for ambiguity in column (1) of table 3 shows that an organization with a mean level of ambiguity (.19) would be seven percent more likely to end in a given year compared to a single-issue organization (with an ambiguity level of 0 ). Compared to single issue TOs, an ambiguity level of one standard deviation above the mean would increase an organization's demise by twenty-two percent.

For those more familiar with hazard ratios, I include these estimates in table $\mathrm{C} 1$ in Appendix C. Ambiguity does not affect the rate at which a TO enters the political system, which can be seen clearly by examining the hazard ratio, which approximates 1.0. This finding is interesting because it suggests that category ambiguity in ideological memberships is neither an obstacle nor a benefit for joining the political process.

Three measures capture the extent to which forces of opposition increase the rate at which TOs fail. First, we see that having a leader either arrested or killed subsequently increases the chances an organization will fold by any means (Cronin 2009; Huo et al 2020). To ensure that I am not using the same event on both sides of the equation (e.g., if an organization's end and its leader's death occurs the same year), I re-coded leadership endings to 0 if this year was 
also the ending year for the organization. The effects are the same either way: removing an organization's leader hastens its demise. Note that a leader's capture or death does not invariably precede an organization's demise. Al-Qaeda, ISIS have suffered numerous losses of leadership, but have managed to survive as organizations.

A second threat to the survival of TOs comes from rivals. Here the impact of rivals is straightforward. Rivals significantly increase the rate of all endings in column (1) and the presence of rivals increases the chances of ending by splitting, military defeat, or fading away in column (2).

Finally, operating internationally might have substantial trade-offs for TOs. While international operations conceivably elevate a TO's profile, such visibility might also increase the chance that counter-terrorist operations will be directed against it (Asal and Young 2012). In columns (1) and (2) we see that organizations that direct a larger share of attacks outside their home base are significantly likely to end, but most of this effect is due to the ending by political means. Speculating further, this result may indicate that TO's that operate internationally might increase global diplomatic pressures on a host country to consider negotiations that could lead to political incorporation of a TO.

Two particular ideological foci impede an organization's ability to end by any means: ethno-nationalist and Islamic terrorist organizations (either singly or in combination with other ideologies) have a lower chance of mortality of any kind. This finding supports the conventional view that religious and ethno-nationalist organizations are more resilient.

Tactical diversity deters the demise of TOs, as expected. This finding is consistent with a host of social movement studies that find that tactical diversity benefits social movement 
organizations such as civil rights' organizations, women's movement, and other types of movement organizations (Olzak and Ryo 2007; Wang, Piazza, and Soule 2018).

Other measures of organizational capacity show the expected influence on survival. Peak size decreases the odds that an organization will end by non-political endings. But in column (2), we see that size has a positive (but insignificant) effect on entering the political system. This finding is consistent with the speculation that TOs that end by entering the political system do so by bargaining from a position of strength. As with similar effects found for other measures of organizational strength, these effects should be interpreted cautiously.

Interaction Effects of Age with Ambiguity and Typicality

The liability of newness argument offers several reasons why organizations fail at younger ages: routines are less developed, their identity is less well-understood and recognized, and their leadership more fragile and less well established. Is the effect of ambiguity more devastating for a younger, more vulnerable TOs? I explore this question in table 4 by examining the same set of endings as presented in table 3: all endings, ending by entering the political system, and ending by splitting or military defeat. For all endings and political endings, I found no significant interaction effects of ambiguity with age. But in column (3), we see a significant interaction effect for the more devastating endings: During the first two years of activity, TOs with highly ambiguous identities fail significantly faster.

[Table 4 about here]

\section{ROBUSTNESS CHECKS}

The fatality analysis used negative binomial model to estimate the effects on the raw counts of fatalities, taking into account the annual number of attacks generated by a TO. Other plausible methods of estimation exist that are also suitable for use with count data. Because there are many 
zero counts in the fatalities data, I first explore zero-inflated negative binomial count models. No differences were found when compared to those reported here. The portion of results that predicts zero fatalities found significant and negative effects of (log) duration and peak size. All other main effects seen in table 2 were replicated, which was reassuring. In particular, ambiguity has a similar, significant, and negative effect on lethality using zero inflated negative binomial regression. But, because this technique pools the data across panels, this method is less than ideal.

I also explored an alternative specification for estimating the effects of issue focus on endings using logistic regression in a panel model (using xtlogit, clustering by organizational identity), where dependent variable is coded 1 if an organization ended (or ended in a specific way) in a given year (see Hou et al. 2020). The results are remarkably similar to those seen in table 3: ambiguity increases the rate of endings by any means and endings other than entering the political system, but it does not affect endings by entering the political system. A measure of duration (since 1970) showed a significant negative effect on the rate of all endings, which is consistent with the results in table 3 . While these results are encouraging, such models cannot incorporate estimates of age-specific rates and their interactions with ambiguity.

\section{DISCUSSION AND CONCLUSIONS}

This analysis of TOs finds support for the argument that ambiguous organizations will suffer disadvantages in terms of tactical performance and survival. TOs that are have ambiguous ideological labels attributed to them accumulate fewer fatalities and end sooner than others. But these factors do not influence all of the ways a TO ends, however. Ambiguity has no effect on the rate at which a TO enters the political process. 
Results shown here supporting the beneficial aspects of having an unambiguous and typical identity are consistent with several studies of SMOs, including the environmental movement (Olzak and Johnson 2019) and the antinuclear movement (Piazza and Wang 2020), and the women's movement (Fassioto and Soule 2017). Another group of scholars have argued the opposite, that social movement organizations that bridge movement areas and have multiple ideological foci will thrive because they are able to broaden their base (Heaney and Rojas 2014; Jung et al. 2014). The evidence presented here supports claims that spanning ideologies impedes tactical performance and curtails survival of many types of organizations, including TOs.

Newly available information on TOs were invaluable to this project and researchers should be eager to further explore these data. In particular, the EDTG dataset offers a more complete picture of active terrorist organizations than has been analyzed previously. By supplementing the GTD database with specific organizational features, Hou et al. (2020) have offered researcher a wealth of new information that can be used to test theories of TOs directly.

As with all datasets, this dataset has limitations. Only two such consequences have been studied here - that of fatalities and survival. Other possible outcomes that ought to be investigated in future research might analyze whether efforts by counter-terrorist forces are more or successful when they are directed against more TOs with ambiguous ideological identities. The results regarding the effects of age dependence suggest another avenue to explore. Ambiguity may also influence TOs at other crucial turning points in their lifecycle, such as those surrounding leadership succession, leadership loss, and internal betrayals.

The names of unknown perpetrators are, by definition, omitted from this dataset. It is likely that organizations or individuals that do not take responsibility for terrorist events might have substantially different or even lack ideological foci. Second, because terrorist organization 
are clandestine organizations, there is considerable missing data on organizational size and membership growth, which substantially reduces the sample size available for analysis.

It might be useful at this point to draw some comparisons with previous work on terrorist organizations here. Many of the beneficial results of organizational size, duration, ethnic, and religious orientation for lethality and survival of TOs reported here have been well-documented in research by leading scholars in this field (Asal and Rethemeyer 2008; Gaibulloev and Sandler 2019; Guo et al. 2020; Jones and Libicki 2008). The finding that a narrow ideological focus has advantages replicates Olzak's (2016) early research that analyzed fewer terrorist organizations and represented very different set of organizations active during an earlier time period.

Findings reported by Hou et al. (2020) are replicated here, especially those concerning the effects of size, and ethno-nationalist and Islamic religious organizations on lethality. ${ }^{8}$ Phillips $(2015,2019)$ work emphasizing the influence of rivals and allies complements and, in some cases, finds differing results here as well. For example, in contrast to Phillips (2015), I find that competition among rivals does not contribute to the longevity of terrorist groups.

Supporting many of the pioneering efforts of Crenshaw, Cronin, Sandler, Asal and Rethemeyer, and others, I find that ethno-nationalist and Islamic organizations remain more

\footnotetext{
${ }^{8}$ Country level variables are not included in the analysis for three reasons: (1) many organizations have bases, recruit, and operate in multiple countries, which raises questions about assigning a single home base to an organization, (2) the theoretical focus here is on organizational characteristics, not country-level contexts, (3) because organizations are nested within countries, the standard errors for the regression coefficients could be underestimated, creating problems for making inferences.
} 
lethal and more durable than organizations affiliated with other ideologies. Together with the ambiguity and typicality results, it is evident that some religious and ethno-nationalist terrorist organizations have endured in part due to ideological purity, which improves their ability to attract those most committed to a cause. Scholars interested in radicalization processes and socialization into TOs could benefit by extending these ideas further.

This paper began by noting that one of the obstacles to studying terrorist organizations stems from their inherent characteristic of having fluid boundaries that means that their members, allies, and forms can shift over time. But they almost never change their ideological affiliations. The analysis presented here suggests that the attribution of membership in one or more ideologies offers some insight about why the assignment of ideological concepts to a TO matters.

A higher proportion of TOs have fewer combinations of distant ideologies attributed to them in this study compared to analyses from earlier periods (Olzak 2016). One reason for this might be due to the winnowing effects of ambiguity, which would be consistent with the fact that the surviving TOs have a narrow ideological focus. The results shown here suggest that these organizations will be harder to defeat.

The key theoretical claim advanced here is that low ambiguity lengthens the lifespan of terrorist organizations, while having multiple and atypical ideological identities hampers their tactical success. The theoretical argument presented here emphasizes how categorical attributions by others might affect the functioning of TOs. Using this newly available EDTG data set, the analysis provides more evidence supporting the idea that category spanning comes with a cost. 


\section{REFERENCES}

Alter, Adam L. and Daniel M. Oppenheimer. 2008. "Easy on the Mind, Easy on the Wallet: The Roles and Familiarity and Processing Fluence on Valuation Judgements." Psychonomic Bulletin Review 15: 985-990.

Asal Victor, Michell Brown, Angela Dalton. 2012. "Why Split? Organizational Splits Among Ethnopolitical Organizations in the Middle East.” Journal of Conflict Resolution 56: 94 117.

Asal, Victor, and Brian J. Phillips. 2015. "What Explains Ethnic Organizational Violence? Evidence from Eastern Europe and Russia." Conflict Management and Peace Science (published online November 27, 2015), doi: 10.1177/0738894215614504. (accessed January 10, 2016).

Asal, Victor H., Paul Gill, R. Karl Rethemeyer, and John Horgan. 2015. “Killing Range: Explaining Lethality Variance within a Terrorist Organization." Journal of Conflict Resolution 59: 401-27. doi: 10.1177/0022002713508927. (accessed January 1, 2015).

Asal, Victor H., Hyun Hee Park, R. Karl Rethemeyer, and Gary Ackerman. 2016. "With Friends Like These...Why Terrorist Organizations Ally.” International Public Management Journal 19(1): 1-30.

Asal, Victor and R. Karl Rethemeyer. 2008. "The Nature of the Beast: Organizational Structures and the Lethality of Terrorist Attacks." The Journal of Politics 70: 437-449.

---. 2009. "Islamic Use and Pursuit of CBRN Terrorism." Pp. 335-358 in Gary Ackerman and Jeremy Tamsett (eds.) Jihadists and the Weapons of Mass Destruction. Boca Raton FL: CRC Press. 
Asal, Victor and R. Karl Rethemeyer, and Ian Anderson. 2008. "Big Allied and Dangerous" (BAAD1) Version 1. http://www.albany.edu/pvc/current_projects.shtml. (accessed June 1, 2011).

Asal, Victor, R. Karl Rethemeyer, and Joseph Young. 2016. "Insurgency BAAD: Dynamics of Terrorism and Counterterrorism Campaigns." National Consortium for the Study of Terrorism and Responses to Terrorism. Research Brief (accessed January 11, 2016). https://www.start.umd.edu/pubs/START_BAAD_CT_October2015.pdf?utm_source=ST ART+Announce\&utm_campaign=19dc6a919f-

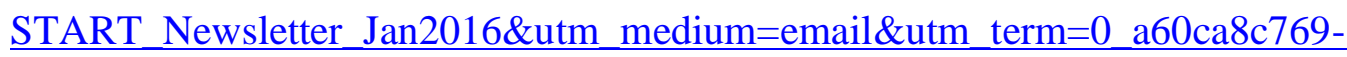
19dc6a919f-14084733 (accessed October 30, 2015).

Asal, Victor and Joseph K. Young. 2012. "Battling Abroad: Why Some Organizations are Likely Targets of Foreign Counterterrorism." Civil Wars 14: 272-287.

Bapat, Navin and Kanisha D. Bond. 2012. "Alliances Amongst Militant Groups.” British Journal of Political Science 42(4): 793-824.

Beck, Colin J. 2008. "The Contribution of Social Movement Theory to Understanding Terrorism,"' Sociology Compass 2(5): 1565-1581, doi:10.1111=j.17519020.2008.00148.x, 1576

Benford, Robert D. and David A. Snow. 2000. "Framing Processes and Social Movements: An Overview and Assessment." Annual Review of Sociology 26: 611-38.

Berman, Eli. 2009. Radical, Religious, and Violent. New Brunswick NJ: Rutgers University Press.

Blomberg, Brock S., Rozlyn C. Engel and Reid Sawyer. 2010. “On the Duration and Sustainability of Terrorist Organizations." Journal of Conflict Resolution 54: 303-330. 
Blomberg, Brock S., Khusrav Gaibulloev, and Todd Sandler. 2011. “Terrorist Group Survival: Ideology, Tactics, and Base of Operations." Public Choice 149: 441-63.

Carroll, Glenn R. and Michael T. Hannan. 2004. The Demography of Corporations and Industries. Princeton NJ: Princeton University Press.

Chou., Winston. 2016. "Seen Like a State: How Illegitimacy Shapes Terrorism Designation." Social Forces 94(5): 1129-1152.

Clauset Aaron and Kristian Skrede Gleditsch. 2012. "The Developmental Dynamics of Terrorist Organizations.” PLoS One 7(11): e48633. doi:10.1371/journal.pone.0048633 (accessed January 15,2016$)$.

Conrad, Justin, and Kevin Green. 2015. "Competition, Differentiation, and the Severity of Terrorist Attacks." The Journal of Politics 77: 546-561.

Crenshaw, Martha. 1987. "Theories of Terrorism: Instrumental and Organizational Approaches." Journal of Strategic Studies 10(4): 13-31.

---1991. "How Terrorism Declines." Terrorism and Political Violence 3: 69-87.

---2011. Explaining Terrorism: Causes, Processes, and Consequences. New York: Routledge.

---. 2020. “Mapping Militant Organizations.” Stanford CA: Stanford University. http://web.stanford.edu/group/mappingmilitants/cgi-bin/groups (accessed June 20, 2015).

Cronin, Audrey Kurth. 2009. How Terrorist Groups End. Princeton NJ: Princeton University Press.

Davenport, Christian. 2015. How Social Movements Die. New York: Cambridge University Press.

della Porta, Donatella. 2013. Clandestine Political Violence. New York: Cambridge University Press. 
Enders, Walter, Todd Sandler, and Khusrav Gaibulloev. 2011. "Domestic Versus Transnational Terrorism: Data, Decomposition, and Dynamics.” Journal of Peace Research 48: 319337.

Fassioto, Magali and Sarah A. Soule. 2017. "Loud and Clear: The Effect of Protest Signals on Congressional Attention.” Mobilization: An International Journal 22(1): 17-38.

Gaibulloev, Khusrav and Todd Sandler. 2013. "Determinants of the Demise of Terrorist Organizations.” Southern Economic Journal 79: 774-92.

---. 2019. "What We Have Learned about Terrorism since 9/11" Journal of Economic Literature 57(2): 275-328.

Gamson, William. 1975. The Strategy of Social Protest. Homewood Ill: Dorsey Press.

Global Terrorism Database (GTD). 2019. Global Terrorism Database. Codebook: Inclusion Criteria and Variables. College Park MD: National Consortium for the Study of Terrorism and Responses to Terrorism. http://www.start.umd.edu/gtd/usinggtd/downloads/Codebook.pdf (accessed March 10, 2019).

Hannan, Michael T., Greta Hsu, Bálasz Kovács, Gaël Le Mens, Giacomo Negro, Lászlo Pólos, Elizabeth G. Pontikes, and Amanda J. Sharkey. 2019. Concepts and Categories: Foundations for Sociological and Cultural Analysis. NY: Columbia University Press.

Hannan, Michael T., Lászlo Pólos, and Glenn R. Carroll. 2007. Logics of Organization Theory: Audiences, Codes, and Ecologies. Princeton NJ: Princeton University Press.

Heaney, Michael T. and Fabio Rojas. 2014. "Hybrid Activism: Social Movement Mobilization in a Multi-Movement Environment.” American Journal of Sociology 119: 1047-1103. 
Horowitz, Michael C. and Philip B. K. Potter. 2014. “Allying to Kill: Terrorist Intergroup Cooperation and the Consequences for Lethality." Journal of Conflict Resolution 58: $199-225$.

Hou, Donfang, Khusrav Gaibulloev, and Todd Sandler. 2020. "Introducing Extended Data on Terrorist Groups (EDTG), 1970 to 2016." Journal of Conflict Resolution 64(1): 199-225.

Hsu, Greta. 2006. “Jacks of All Trades and Masters of None: Audiences' Reactions to Spanning Genres in Feature Film Production.” Administrative Science Quarterly 512: 420-450. http://dx/doi.org/10.2189/asqu.51.3.420.

Jones, Seth G., and Martin C. Libicki. 2008. "How Terrorist Groups End.” Santa Monica CA: Rand Corporation.

Jung, W. Brayden G. King, and Sarah A. Soule. 2014. "Issue Bricolage: Explaining the Configuration of the Social Movement Sector, 1960-1995." American Journal of Sociology 120(1): 187-225.

Kinney, Alexander B., Andrew P. Davis, and Yongjun Zhang. 2018. “Theming for Terror: Organizational Adornment in Terrorist Propaganda." Poetics 69: 27-40.

Kovács, Balász and Michael T. Hannan. 2010. “The Consequences of Category Spanning Depend on Contrast.” In Hsu Greta, Giacomo Negro, Özgecan Koçak (eds.), Research in the Sociology of Organizations 31: 175-201. Bingley, UK: Emerald Book.

---. 2015. "Conceptual Spaces and the Consequences of Category Spanning." Sociological Science. 2: 258-286. DOI: 10.15195/v2.a13

LaFree, Gary and Laura Dugan. 2009. "Research on Terrorism and Countering Terrorism." Crime and Justice 38: 413-477. 
LaFree, Gary, Laura Dugan, and Erin Miller. 2015. Putting Terrorism in Context. NY:

Routledge.

Le Mens, Gaël, Michael T. Hannan, and Lásló Pólos. 2011. "Founding Conditions, Learning, and Organizational Life Chances: Age Dependence Revisited.” Administrative Science Quarterly 56: 95-126.

McCarthy, John D. and Mayer Zald. 1977. "Resource Mobilization and Social Movements: A Partial Theory.” American Journal of Sociology 82: 1212-1241.

Negro, Giacomo, Özgeçan Koçak and Greta Hsu. 2010. "Research on Categories in the Sociology of Organizations.” Research in the Sociology of Organizations 31: 1-35.

Nemeth, Stephen. 2014. “The Effect of Competition on Terrorist Group Operations.” Journal of Conflict Resolution 58: 336-62.

Olzak, Susan. 2016. “The Effect of Category Spanning on the Lethality and Longevity of Terrorist Organizations.” Social Forces 95 (2): 559-584. doi: 10.1093/sf/sow081

Olzak, Susan and Erik Johnson. 2019. The Risk of Occupying a Broad Niche for Environmental Social Movement Organizations.” Mobilization: An International Quarterly 24(2): 177198.

Olzak, Susan and Emily Ryo. 2007. “Organizational Diversity, Vitality and Outcomes in the African American Civil Rights Movement.” Social Forces 85: 1561-1592.

Phillips, Brian J. 2014. “Terrorist Group Cooperation and Longevity.” International Studies Quarterly 58(June) 336-347.

---. 2015. "Enemies with Benefits? Violent Rivalry and Terrorist Group Longevity." Journal of Peace Research 52: 62-75. 
---. 2019. "Terrorist Group Rivalries and Alliances: Testing Competing Explanations." Studies in Conflict \& Terrorism 42(11: 997-1019.

Piazza, Alessandro and Dan J. Wang. 2020. "Claim Specialization, Tactical Diversity and the Protest Environment in the Success of U.S. Antinuclear Activism.” Mobilization 25(1): 93-114.

Piazza, James A. 2009. "Is Islamic Terrorism More Dangerous?: An Empirical Study of Group Ideology, Organization, and Goal Structure.” Terrorism and Political Violence 21: 6288.

Piazza, James A. and Gary LaFree. 2019. "Islamic Terrorism, Diaspora Links and Casualty Rates." Perspectives on Terrorism 13(5): 2-21.

Post, Jerrold M., Ehud Sprinzak, and Laurita M. Denny. 2003. "The Terrorist in Their Own Words: Interviews with 35 Incarcerated Middle Eastern Terrorists.” Terrorism and Political Violence 15: 171-184.

Sandler, Todd. 2014. "The Analytical Study of Terrorism: Taking Stock." Journal of Peace Research 51: 257-71.

---. 2015. “Terrorism and Counterterrorism: An Overview.” Oxford Economic Papers 2015: 120.

Selznick, Phillip. 1960 The Organization Weapon. Glencoe IL: Free Press.

Schuurman, Bart, and Max Taylor. 2018. "Reconsidering Radicalization: Fanaticism and the Link Between Ideas and Violence." Perspectives on Terrorism 12(1): 3-21.

Shepard, Roger N. 1964. "Attention and the Metric Structure of the Stimulus Space." Journal of Mathematical Psychology 1(1): 54-87. 
Sørensen, Jesper B. 2002. "The Strength of Corporate Culture and the Reliability of Firm Performance." Administrative Quarterly 47(1): 70-91.

Stinchcombe, Arthur. 1965. "Social Structure and Organizations," Pp. 142-193 in James March (ed.) Handbook of Organizations. Chicago IL: Rand McNally.

Tilly, Charles. 2004. “Terror, Terrorism, Terrorists.” Sociological Theory 22(1): 5-13.

Valentino, Benjamin A. 2014. "Why We Kill: The Political Science of the Political Violence Against Civilians." Annual Review of Political Science 17:89-103.

Wang, Dan, Alessandro Piazza, and Sarah A. Soule. 2018. "Boundary-Spanning in Social Movements: Antecedents and Outcomes.” Annual Review of Sociology 44: 167-187.

Webber, David, Arie Kruglanski, Erica Molinario, and Katarzyna Jasko. 2020. "Ideologies That Justify Political Violence.” Current Opinion in Behavioral Sciences 34:107-111.

Young, Joseph K. and Laura Dugan. 2014. "Survival of the Fittest: Why Terrorist Groups Endure." Perspectives on Terrorism 8(2): 1-22. 
Table 1: Ideological Categories Associated with Levels of Ambiguity

\begin{tabular}{|c|c|c|c|}
\hline Ideological Labels Assigned by Archivists & Frequency & Percent & Ambiguity \\
\hline Ethno-nationalist only & 120 & 24.8 & 0 \\
\hline Leftist/Marxist only & 95 & 19.7 & 0 \\
\hline Islamicist only 302 & 75 & 15.5 & 0 \\
\hline Religious but Not Islamic only & 4 & .8 & 0 \\
\hline Right-wing only & 12 & .25 & 0 \\
\hline Environmental only & 2 & .4 & 0 \\
\hline Anarchist only & 4 & .8 & 0 \\
\hline Racist/Genocide only & 2 & .4 & 0 \\
\hline Other/none only & 10 & 2 & 0 \\
\hline Tribal only & 3 & .6 & 0 \\
\hline Leftist \& Ethno-nationalist & 22 & 4.6 & .635 \\
\hline Leftist \& Anarchist & 12 & 2.3 & .366 \\
\hline Leftist \& Anti-globalization & 1 & .2 & .217 \\
\hline Leftist \& Racist & 1 & .2 & .458 \\
\hline Leftist \& Other & 2 & .4 & .490 \\
\hline Leftist \& Islamic & 1 & .2 & .727 \\
\hline Leftist \& Not Islamic & 1 & .2 & .366 \\
\hline Ethno-nationalist \& Islamic & 48 & 9.9 & .712 \\
\hline Ethno-nationalist \& Relig. Not Islamic & 5 & 1.0 & .235 \\
\hline Ethno-nationalist \& Racist/Genocide & 6 & 1.2 & .309 \\
\hline Ethno-nationalist \& Other & 4 & .8 & .338 \\
\hline Relig. Not Islamic \& Right & 3 & .6 & .622 \\
\hline Relig. Not Islamic \& Racist & 1 & .2 & .671 \\
\hline Relig. Not Islamic \& Other & 3 & .6 & .655 \\
\hline Right \& Ethno-nationalist & 5 & 1.0 & .622 \\
\hline Right \& Racist & 5 & 1.0 & .673 \\
\hline Right \& Other & 3 & .6 & .685 \\
\hline Racist \& Relig. Not Islamic & 1 & .2 & .672 \\
\hline Racist \& Islamic & 2 & .4 & .558 \\
\hline Ethno-nationalist \& Right \& Racist & 1 & .2 & .657 \\
\hline Ethno-nationalist \& Left \& Racist & 1 & .2 & .831 \\
\hline Ethno-nationalist \& Islamic \& Racist & 1 & .2 & .847 \\
\hline Ethno-nationalist \& Not Islamic \& Racist & 1 & .2 & .519 \\
\hline Ethno-nationalist \& Tribal \& Islamic & 1 & .2 & .672 \\
\hline Ethno-nationalist \& Left \& Anti-globaliz. & 1 & .2 & .719 \\
\hline Ethno-nationalist \& Not Islamic \& Right & 2 & .4 & .588 \\
\hline Right \& Not Islamic \& Racist & 1 & .2 & 1.05 \\
\hline Left \& Anarchist \& Anti-globalization & 2 & .4 & .547 \\
\hline Racist \& Islamic \& Anti-globalization & 1 & .2 & .644 \\
\hline
\end{tabular}


Table 2. Negative Binomial Estimates of the Effect of Conceptual Ambiguity and Typicality on the Lethality of Terrorist Organizations, 1970 to 2017

\begin{tabular}{|c|c|}
\hline Covariates & Lethality \\
\hline \multirow[t]{2}{*}{ Ambiguity } & $-.450 * * *$ \\
\hline & $(.123)$ \\
\hline \multirow[t]{2}{*}{ Has Rival $(0,1)$} & $-.275 * * *$ \\
\hline & $(.062)$ \\
\hline \multirow[t]{2}{*}{ Has Ally } & $-.215 * * *$ \\
\hline & $(.059)$ \\
\hline \multirow[t]{2}{*}{ Peak Size in $1000 \mathrm{~s}$} & $.032 * * *$ \\
\hline & $(.007)$ \\
\hline \multirow[t]{2}{*}{ Tactical Diversity } & $-.260 * *$ \\
\hline & $(.092)$ \\
\hline $\begin{array}{l}\text { Share of International } \\
\text { Terrorist Acts }\end{array}$ & $\begin{array}{l}.010 \\
(.076)\end{array}$ \\
\hline \multirow[t]{2}{*}{ Ethnic/Nationalist $(0,1)$} & $.447 * * *$ \\
\hline & $(.072)$ \\
\hline \multirow[t]{2}{*}{ Islamicist $(0,1)$} & $.717 * * *$ \\
\hline & $(.086)$ \\
\hline \multirow[t]{2}{*}{ Ln Duration } & $-.119 * * *$ \\
\hline & $(.029)$ \\
\hline \multirow[t]{2}{*}{ Number of Bases $(0,1)$} & $.242 * * *$ \\
\hline & $(.035)$ \\
\hline \multirow[t]{2}{*}{ Post $911(0,1)$} & $-.177 * *$ \\
\hline & $(.060)$ \\
\hline \multirow[t]{2}{*}{ Active Before $1970(0,1)$} & $.315^{* *}$ \\
\hline & .095 \\
\hline \multirow[t]{2}{*}{ Constant } & $-2.389 * * *$ \\
\hline & $(.130)$ \\
\hline Log Likeihood & -7780.9 \\
\hline Observations & 6699 \\
\hline Number of Organizations & 483 \\
\hline
\end{tabular}


Table 3. Piecewise Exponential Estimates of the Rate of Ending

\begin{tabular}{|c|c|c|c|}
\hline Covariates: & $\begin{array}{l}\text { Ended by Any } \\
\text { Means } \\
\text { (1) }\end{array}$ & $\begin{array}{l}\text { Ended by } \\
\text { Entering the } \\
\text { Political System } \\
\quad \text { (2) }\end{array}$ & $\begin{array}{l}\text { Ended by Splits, } \\
\text { Military Defeat, or } \\
\text { Fading Away } \\
\text { (3) }\end{array}$ \\
\hline \multirow[t]{2}{*}{ Age $<0$ to 2 years } & $-2.07 * * *$ & $-2.61 * * *$ & $-2.67 * * *$ \\
\hline & $(.389)$ & $(.534)$ & $(.597)$ \\
\hline \multirow[t]{2}{*}{ Age 3 yrs > 14 yrs } & $-2.77 * * *$ & $-3.81 * * *$ & $-3.19 * * *$ \\
\hline & $(.399)$ & $(.549)$ & $(.590)$ \\
\hline \multirow[t]{2}{*}{ Age $15+$ years } & $-2.78 * * *$ & $-3.14 * * *$ & $-3.45^{* * *}$ \\
\hline & $(.416)$ & $(.423)$ & $(.614)$ \\
\hline \multirow[t]{2}{*}{ Ambiguity } & $.417^{*}$ & .062 & $.544^{*}$ \\
\hline & $(.208)$ & $(.423)$ & $(.252)$ \\
\hline \multirow[t]{2}{*}{ Leader Killed/Arrest } & $1.07 * * *$ & $1.05^{* * *}$ & $.971^{* *}$ \\
\hline & $(.243)$ & $(.480)$ & $(.288)$ \\
\hline \multirow[t]{2}{*}{ Has Rival $(0,1)$} & $.698^{*}$ & -.254 & $1.11^{* * * *}$ \\
\hline & $(.355)$ & $(.442)$ & $(.534)$ \\
\hline \multirow[t]{2}{*}{ Has Ally $(0,1)$} & $-.845 * * *$ & $-.931 * * *$ & $-.883 * * *$ \\
\hline & $(.140)$ & $(.261)$ & $(.153)$ \\
\hline \multirow[t]{2}{*}{ Peak Size 1000s } & $-.056 * *$ & .039 & $-.158 * *$ \\
\hline & $(.024)$ & $(.031)$ & $(.059)$ \\
\hline \multirow[t]{2}{*}{ Tactical Diversity } & $-2.43 * * *$ & $-2.08^{*}$ & $-2.47 * * *$ \\
\hline & $(.432)$ & $(.810)$ & $(.529)$ \\
\hline $\begin{array}{l}\text { Share of International } \\
\text { Events }\end{array}$ & $\begin{array}{l}.683 * * * \\
(.172)\end{array}$ & $\begin{array}{c}1.44 * * * \\
(.320)\end{array}$ & $\begin{array}{l}.340 \\
(.219)\end{array}$ \\
\hline Ethnic/Nationalist & $-.466 * * *$ & -.452 & $-.498 * *$ \\
\hline$(0,1)$ & $(.122)$ & $(.223)$ & $(.159)$ \\
\hline Islamicist & $-.686 * * *$ & $-1.85 * * *$ & $-.570^{* *}$ \\
\hline$(0,1)$ & $(.182)$ & $(.499)$ & $(.218)$ \\
\hline \multirow[t]{2}{*}{ Number of Bases } & .037 & .006 & -.063 \\
\hline & $(.063)$ & $(.096)$ & $(.084)$ \\
\hline \multirow[t]{2}{*}{ Post $911(0,1)$} & .114 & -.168 & .174 \\
\hline & $(.156)$ & $(.279)$ & $(.198)$ \\
\hline \multirow[t]{2}{*}{ Ln Attacks } & $.006^{* * * *}$ & .068 & $.160 * * *$ \\
\hline & $(.001)$ & $(.042)$ & $(.025)$ \\
\hline Active Before 1970 & $-.531 * * *$ & -.109 & $-.855^{*}$ \\
\hline$(0,1)$ & $(.193)$ & $(.321)$ & $(.359)$ \\
\hline Observations & 6757 & 6757 & 6757 \\
\hline Number TOs & 487 & 487 & 487 \\
\hline Number of Endings & 273 & 87 & 178 \\
\hline
\end{tabular}

Notes: Robust standard errors in parentheses. ${ }^{* * *} \mathrm{p}<0.001,{ }^{* *} \mathrm{p}<0.01,{ }^{*} \mathrm{p}<0.05$, Twotailed tests reported. 
Table 4. Interaction Effects of Age and Ambiguity on the Rate of Ending

\begin{tabular}{|c|c|c|c|}
\hline Age*Ambiguity Interactions & $\begin{array}{l}\text { Ended by Any } \\
\text { Means } \\
\qquad(1) \\
\end{array}$ & $\begin{array}{l}\text { Ended by Entering } \\
\text { the Political System } \\
\text { (2) }\end{array}$ & $\begin{array}{l}\text { Ended by Splits, } \\
\text { Military Defeat, or } \\
\text { Fading A way } \\
\text { (3) } \\
\end{array}$ \\
\hline \multirow[t]{2}{*}{ Age $<0$ to 2 years } & $-2.07 * * *$ & $-2.56^{* * *}$ & $-2.73^{* * *}$ \\
\hline & $(.039)$ & $(.536)$ & $(.584)$ \\
\hline \multirow[t]{2}{*}{ Age 3 yrs > 14 yrs } & $-2.75 * * *$ & $--3.90 * * *$ & $-3.13 * * *$ \\
\hline & $(.040)$ & $(.561)$ & $(.588)$ \\
\hline \multirow[t]{2}{*}{ Age $15+$ years } & $-2.80 * * *$ & $-3.16^{* * *}$ & $-3.48^{* * *}$ \\
\hline & $(.433)$ & $(.550)$ & $(.637)$ \\
\hline \multirow[t]{2}{*}{ Ambiguity $* 0$ to 2 yrs } & .390 & -.487 & $.858^{*}$ \\
\hline & $(.329)$ & $(.702)$ & (.411) \\
\hline \multirow[t]{2}{*}{ Ambiguity $* 3$ to 14 yrs } & .342 & .579 & .246 \\
\hline & (.339) & $(.769)$ & (.397) \\
\hline \multirow[t]{2}{*}{ Ambiguity $* 15+$ years } & .577 & .158 & .664 \\
\hline & (.430) & $(.723)$ & $(.561)$ \\
\hline Table 3 covariates included? & yes & yes & yes \\
\hline Observations & 6757 & 6757 & 6757 \\
\hline Number TOs & 487 & 487 & 487 \\
\hline Number of Endings & 273 & 87 & 178 \\
\hline
\end{tabular}

Notes: Hazard ratios from analysis shown in table 3 for key theoretical variables. Robust standard errors in parentheses. ${ }^{* * *} \mathrm{p}<0.001,{ }^{* *} \mathrm{p}<0.01,{ }^{*} \mathrm{p}<0.05$ (two-tailed tests) 


\section{APPENDIX A}

\section{Measuring Ambiguity}

Three steps are involved in generating estimates of ambiguity from categorizations The first step uses information on the distribution of ideological categories across organizations to calculate a Jaccard similarity/dissimilarity index for each pair of categories. The second step involves calculation of typicalities, which are then used in the third step to calculate ambiguity.

\section{Jaccard Similarity/Dissimilarity}

The similarity of a pair of categories can be calculated using the Jaccard index (Kovács and Hannan 2015). Formally, if $|i \quad j|$ denotes the number of organizations categorized as belonging to category $\mathrm{i}$ and label $\mathrm{j}$, and $|i \quad j|$ denotes the number of organizations that are categorized as

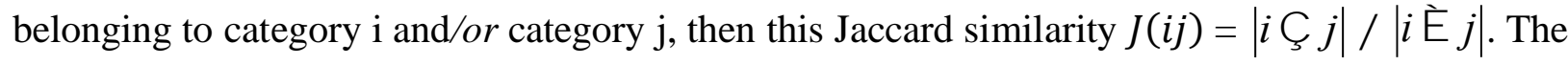
Jaccard distance, $d_{\mathrm{ij}}$, between a pair of categories is 1- $(J(i j))$. The Jaccard distance measured takes values in the $[0,1]$ range with 1 indicating perfect dissimilarity and 0 indicating perfect similarity.

\section{Typicality}

The typicality of an organization with respect to a concept is defined as the probability that it will be classified as member of that concept (Hannan et al. 2019. Typicality depends upon an object's proximity to the schema for the concept. Schemas are cognitive representations of a set of the profiles of prototypical features of a given concept. At the high end of typicality, an entity will be perceived as being a representative instance of a concept because it has been perceived as being closer to the prototype features associated with that concept. 
According to Kovács and Hannan (2015: 257) typicality in any concept falls with: “(1) the number of labels used to describe it; and (2) the distances among the schemas associated with those labels" (Kovács and Hannan 2015: 257). Given that the data provide categorizations but not the values of the features relevant for categorization, I follow Kovács and Hannan (2015) and measure the typicality of an organization $o$ as a $c$ as

$$
\tau(c, o)=\frac{l(c, o)}{1+\sum_{c, c^{\prime}} l(c, o) l\left(c^{\prime}, o\right) d\left(c, c^{\prime}\right)},
$$

where $l(c, o)$ is an indicator that equals one if organization $o$ is labeled as a $c$ and equals zero otherwise; and $d\left(c, c^{\prime}\right)$ is the Jaccard distance between the categories $c$ and $c^{\prime}$. According to this measure, an organization with a single categorization has typicality of one in the assigned label and zero for all of the others. An organization that has two categorical assignments, say $c$ and $c^{\prime}$, has $\tau(c, o)=\tau\left(c^{\prime}, o\right)=1 / 1+d\left(c, c^{\prime}\right)$. Average typicality $T_{(o)}$ over the assigned concepts is measured

$$
\mathrm{T}(o)=\frac{\sum_{c} \tau_{c, o}}{\Sigma_{c} l(c, o)}
$$

\section{Ambiguity}

Because we do not observe feature values, only categorizations, we cannot estimate $P(d x)$ needed for calculating ambiguity (see Eq. 1 in the text). Following Hannan et al. (2019: 177-179) we can approximate $P(d x)$ as:

$$
P^{*}(c)=\frac{T_{c}(o) P_{c}}{\sum_{c} \mathrm{~T}_{c}},
$$

Where $P_{c}$ is the so-called prior on $c$, which we estimate using the observed population of objects categorized as $c$. In terms of this approximation we calculation an approximation to $A(o)$ :

$$
\mathrm{A}^{*}(o)=-\sum_{c \in C} P^{*}(c) \log \left(P^{*}(c)\right),
$$




\section{APPENDIX B}

Table B1. Means, Standard Deviations and Correlation Matrix for Covariates in Lethality Analysis (Table 2)

\begin{tabular}{|c|c|c|c|c|c|c|c|c|c|c|c|c|c|c|c|}
\hline | & Mean & $\begin{array}{l}\text { Std. } \\
\text { Dev }\end{array}$ & 1 & 2 & 3 & 4 & 5 & 6 & 7 & 8 & 9 & 10 & 11 & 12 & 13 \\
\hline \multicolumn{16}{|l|}{ Covariates: } \\
\hline 1 Ambiguity & .19 & .29 & 1 & & & & & & & & & & & & \\
\hline 2 Has Rival $(0,1)$ & .89 & .31 & -.11 & 1 & & & & & & & & & & & \\
\hline 3 Has Ally $(0,1)$ & .46 & .49 & .14 & -.21 & 1 & & & & & & & & & & \\
\hline 4 Peak Size in 1000 s & 1.8 & 3.4 & -.13 & -.00 & .08 & 1 & & & & & & & & & \\
\hline 5 Tactical Diversity & .10 & .21 & .04 & -.08 & .17 & .11 & 1 & & & & & & & & \\
\hline $\begin{array}{l}6 \text { Share of } \\
\text { Transnational Acts }\end{array}$ & .10 & .26 & .18 & .03 & .03 & -.03 & .26 & 1 & & & & & & & \\
\hline $\begin{array}{l}7 \text { Ethno-Nationalist } \\
(0,1)\end{array}$ & .54 & .49 & .28 & -.05 & .02 & .05 & -.00 & -.01 & 1 & & & & & & \\
\hline 8 Islamicist $(0,1)$ & .28 & .45 & .26 & -.19 & $\begin{array}{l}- \\
.05\end{array}$ & -.08 & -.00 & -.06 & -.25 & 1 & & & & & \\
\hline 9 Ln Duration & 2.2 & 1.0 & -.00 & -.07 & .22 & .09 & .07 & -.15 & .06 & -.04 & 1 & & & & \\
\hline 10 Number of Bases & .31 & .46 & .01 & -.02 & .10 & -.10 & -.07 & .02 & .12 & -.02 & .09 & 1 & & & \\
\hline 11 Post911 $(0,1)$ & .41 & .49 & .03 & -.26 & -.03 & -.04 & -.01 & -.15 & .05 & .24 & .23 & -.12 & 1 & & \\
\hline $\begin{array}{l}12 \text { Active Before } \\
1970(0,1)\end{array}$ & .16 & .36 & .08 & .13 & .14 & .16 & .01 & .01 & .12 & -.18 & .21 & .08 & -.18 & 1 & \\
\hline $\begin{array}{l}13 \text { Number of } \\
\text { Attacks }\end{array}$ & 6.6 & 41. & .05 & .02 & .08 & .12 & .33 & .02 & .04 & .05 & .04 & -.06 & .03 & -.02 & 1 \\
\hline
\end{tabular}




\section{Appendix C}

Table C1. Hazard Ratios for Effects of Age, Ambiguity, and Typicality on Rate of Endings (Source: Table 3, columns 1, 2 and 3)

\begin{tabular}{lccc}
\hline \hline & $\begin{array}{l}\text { Ended by Any } \\
\text { Means }\end{array}$ & $\begin{array}{l}\text { Ended by Entering } \\
\text { Politics }\end{array}$ & $\begin{array}{l}\text { Ended by Splits, } \\
\text { Military Defeat, or } \\
\text { Fading Away }\end{array}$ \\
\hline Age<0 to 2 years & $.127 * * *$ & $.074 * * *$ & $.069 * * *$ \\
Age 3 yrs $>14$ yrs & $(.049)$ & $(.039)$ & $(.040)$ \\
Age $15+$ years & $.063 * * *$ & $.023^{* * *}$ & $.041^{* * *}$ \\
Ambiguity & $(.025)$ & $(.012)$ & $(.024)$ \\
Covariates included? & $.063 * * *$ & $.043 * * *$ & $.031^{* * *}$ \\
Observations & $(.026)$ & $(.023)$ & $(.019)$ \\
Number TOs & $1.52 *$ & 1.06 & $1.72 *$ \\
Number of Endings & $(.316)$ & $(.450)$ & $(.434)$ \\
\hline
\end{tabular}

Notes: Hazard ratios from analysis shown in table 3 for key theoretical variables. Robust standard errors in parentheses. $* * * \mathrm{p}<0.001, * * \mathrm{p}<0.01, * \mathrm{p}<0.05$ (two-tailed tests). 